\title{
Fontes para a história dos 50 anos do Ministério da Saúde
}

\author{
Sources for a bistory of the \\ Brazilian Ministry of \\ Health's fifty years
}

\author{
Ana Luce Girão Soares de Lima \\ Departamento de Arquivo e Documentação da Casa de Oswaldo Cruz/Fiocruz \\ analucelima@uol.com.br \\ analuce@coc.fiocruz.br
}

Maria Marta Saavedra Pinto

Núcleo de Disseminação da Informação do DAD/COC/Fiocruz saavedra@coc.fiocruz.br

\begin{abstract}
LIMA, A. L. G. S. de e PINTO, M. M. S.: 'Fontes para a história dos 50 anos do Ministério da Saúde'. História, Ciências, Saúde-Manguinhos, vol. 10(3): 1037-51, set.-dez. 2003. Este trabalho e um levantamento das fontes sobre a história do Ministério da Saúde existentes no acervo da Casa de Oswaldo Cruz/Fiocruz. Utilizamos como marcos cronológicos os cinqüenta anos anteriores à lei 1.920, de 25 de julho de 1953 , que separou a saúde e a educação em pastas autônomas. Nesse período foram lançadas as bases que fundamentariam as políticas públicas de saúde e informariam a estrutura do futuro ministério. Privilegiou-se aqui também a ação dos sanitaristas e intelectuais que figuraram como atores importantes no processo de construção ideológica não só das estruturas de Estado, como também das próprias políticas.
\end{abstract}

PALAVRAS-CHAVE: Ministério da Saúde, história, Brasil República, instituições governamentais, sanitaristas.

LIMA, A. L. G. S. de e PINTO, M. M. S.: 'Sources for a history of the Brazilian Ministry of Health's fifty years'. História, Ciências, Saúde - Manguinhos, vol. 10(3): 1037-51, Sept.Dec. 2003.

This article is fruit of a survey of sources on the bistory of the Ministry of Health that are part of the Fiocruz collection held at Casa de Oswaldo Cruz's Department of Arquives and Documentation. The study spans the fifty years preceding Brazilian Law 1.920 (July 25, 1953), which placed health and education in separate ministries. It was during this period that the foundations which were to sustain public health policies and the ministry's future structure were laid. The study also looks at the activities of the sanitarians and intellectuals who were important actors in the process of ideological construction not only of State structures but of the policies themselves.

KEYWORDS: Ministry of Health, history, Brazilian Republic, governmental institutions, sanitarians. 


\section{Introdução}

Z m 2003, o Ministério da Saúde completa cinqüenta anos de criação, instituído pela lei 1.920 de 25 de julho de 1953. Originário do antigo Ministério da Educação e Saúde, teve como contexto histórico e político de surgimento as questões relativas à centralização dos serviços de saúde e a progressiva separação entre saúde pública e assistência médica. O processo de criação do atual ministério vinha, desde 1946, caracterizando-se pela gradativa ampliação da responsabilidade do governo na defesa e proteção da saúde da população, respaldada pelo ideário da Organização Mundial de Saúde (OMS).

O surgimento de uma pasta autônoma para a saúde pública, por meio da criação de um ministério, mobilizou diversos atores, entre eles políticos, médicos e sanitaristas que atuavam no cenário político das mudanças operadas no país com a Revolução de 1930. Em segundo plano estava a questão de uma possível centralização dos serviços de saúde, até então fragmentados.

É nesse sentido que a Fundação Oswaldo Cruz (Fiocruz) tem papel de destaque nas comemorações dos cinqüenta anos do Ministério da Saúde: a atuação de médicos sanitaristas desta instituição se entrelaça com a construção da história da saúde pública no Brasil. Seja por meio da formulação e discussão de políticas públicas de saúde; seja de pesquisas para a produção de vacinas e medicamentos, e da inovação tecnológica da área de saúde; ou, ainda, pela preservação da memória da história da saúde pública, com seu vasto acervo arquitetônico, documental e museológico, sob a guarda da Casa de Oswaldo Cruz (COC).

A pouca produção historiográfica referente aos anos após 1950 e a ampliação sistemática do recolhimento e preservação de documentos que forneçam subsídios para a pesquisa histórica, como fontes, fazem com que a Casa de Oswaldo Cruz implemente projetos estratégicos, estimulando a guarda para pesquisa de períodos mais recentes da história da saúde pública no Brasil. Essa unidade constitui um centro de referência de pesquisa, coleta, preservação e divulgação de documentos arquivísticos e bibliográficos no campo da história da saúde e das ciências biomédicas, com um acervo de fundamental importância para a história da saúde pública no Brasil e também na América e no Caribe.

Na COC há inúmeros documentos que retratam a trajetória de atores e instituições que compõem a estrutura organizacional da saúde, sob a égide do Ministério da Saúde. Esses personagens são veículos da manifestação de idéias, interesses e propostas de segmentos profissionais, instituições e grupos políticos. Quanto aos acervos de períodos mais recentes - a partir da década de 1950 - , podem ser mencionados os referentes às campanhas de erradicação da varíola, da poliomielite e do sarampo; os programas de imunizações e campanhas sanitárias por 
todo o Brasil, assim como os serviços especiais (febre amarela, tuberculose, malária, câncer e de saúde pública). Também merece destaque o Arquivo da VIII Conferência Nacional de Saúde, ocorrida em Brasília em 1986, pela atualidade das teses ali defendidas há quase vinte anos - e agora retomadas para novo debate durante a $12^{\underline{a}}$ Conferência Nacional de Saúde, a se realizar nos próximos dias. Considera-se aquele evento como o 'berço' do Sistema Único de Saúde (SUS), que orientou a política de assistência médica do Ministério da Saúde após a extinção do Instituto Nacional de Assistência Médica da Previdência Social (Inamps).

O uso de fontes documentais para a compreensão da constituição de órgãos e projetos governamentais de saúde pública é imprescindível para a construção do histórico da saúde e das ciências biomédicas no Brasil. A idéia da criação de um único ministério nos leva a refletir sobre a importância de seus atores e das escolhas para a definição dos projetos políticos dessa área. Entre os atores têm destaque os médicos e sanitaristas que sempre se fizeram presentes nas discussões políticas do campo de saúde pública, ao longo da primeira metade do século XX. Por exemplo, Belisário Penna, para quem o saneamento dos sertões aparecia como questão nacional; Clementino Fraga, sob cuja direção observou-se uma profunda reformulação dos serviços de saúde urbano e rural, com sua descentralização; e finalmente Carlos Chagas, que, além de implantar uma grande reforma sanitária, em 1920, investiu e implementou cursos de formação de recursos humanos para a saúde.

Também destacam-se instituições que, por suas estruturas investidas de definições políticas, ajudam a reconstrução da memória da Saúde Pública no Brasil. Pode-se citar a própria Fiocruz, desde seus primórdios marcada por sua condição de órgão de investigação, pesquisa e produção de vacinas e medicamentos para o bem-estar da saúde da população. Ainda nessa linha de ação destacam-se órgãos como o Departamento Nacional de Endemias Rurais (DNERu) — que organizava e executava serviços de investigação e combate a várias endemias; o Serviço Especial de Saúde Pública (SESP) — responsável pela implementação de técnicas necessárias no campo do saneamento e da assistência médico-sanitária; e a Escola Nacional de Saúde Pública (ENSP) - que se incumbe da formação e aperfeiçoamento de pessoal.

Assim, a COC possui um acervo importante no que diz respeito ao tema. Optamos por abordar, neste primeiro levantamento de fontes, o período relativo ao que se poderia designar como antecedentes da criação do Ministério da Saúde, ou seja, o intervalo entre os anos de 1903 a 1953. Os últimos cinqüenta anos estão igualmente bem documentados e serão objeto de novo artigo, a ser publicado oportunamente. 


\section{A criação do Ministério da Saúde}

Segundo artigos de Fonseca e Hamilton veiculado nesta edição (pp. 791-825) e de Hamilton (1993, p. 3), houve dois projetos que influenciaram a conjuntura de debates sobre o modelo a ser encampado pelo futuro Ministério da Saúde: um deles mantinha praticamente inalterado o modelo do Departamento Nacional de Saúde (DNS); o outro pretendia juntar em uma única secretaria os serviços de saúde pública e de assistência médica da Previdência Social.

A estrutura original do Ministério da Saúde foi herdada do DNS, e sua criação deu início à reorganização das ações de saúde, acabando com a pulverização de recursos financeiros. Os serviços de saúde vinculados ao Ministério da Saúde se organizaram por meio das ações de saúde coletiva. A assistência médica individual e curativa ficaria vinculada à área da Previdência Social, às instituições filantrópicas e à medicina privada.

Apesar da criação do Ministério da Saúde ter sido em 25 de julho de 1953, consideramos importante salientar períodos anteriores, marcados por políticas públicas que destacaram a atuação de certos órgãos, e nas quais fica evidente a atuação de determinados personagens importantes para a história da saúde pública no Brasil. Aproveitando a periodização proposta por Fonseca (1996), e acrescentando mais um período relativo às duas primeiras décadas do século XX, foi possível orientar este trabalho segundo o recorte de fontes importantes do acervo do DAD/ COC/Fiocruz para a trajetória do Ministério da Saúde. Propomos, portanto, a seguinte periodização: primeiro período, de 1903 a 1920; segundo período, de 1920 a 1930; terceiro período, de 1930 a 1953.

\section{Os anos $1903-20$}

De acordo com Hochman (1998), o movimento sanitarista é dividido em dois períodos fundamentais: o primeiro corresponde à primeira década do século XX (1903-09) e foi marcado pela gestão de Oswaldo Cruz à frente dos serviços federais de saúde; nele privilegiaram-se o saneamento urbano da cidade do Rio de Janeiro e o combate às epidemias de febre amarela, peste e varíola.

A segunda fase (1910-20) tem como característica a ênfase no saneamento rural, em especial o combate a três endemias rurais: ancilostomíase, malária e a então recém-descoberta doença de Chagas. O início coincide com a iniciativa do Instituto Oswaldo Cruz (IOC) de realizar expedições científicas ao interior do Brasil, com o objetivo de conhecer as condições de saúde das populações desta área. ${ }^{1}$

\footnotetext{
${ }^{1}$ Sobre o tema, ver Casa de Oswaldo Cruz/Fiocruz, (1991) e Casa de Oswaldo Cruz/Fiocruz (1996).
} 
Belisário Penna escreveu vários artigos - hoje constantes do acervo no Departamento de Arquivo e Documentação da Casa de Oswaldo Cruz - de grande repercussão. Publicados pela imprensa da época, versavam sobre saúde, saneamento e sobretudo a importância da educação sanitária para o desenvolvimento político, econômico e social do país.

Outra iniciativa de destaque no período foi a expedição científica organizada pelo IOC, em 1912, chefiada por Belisário Penna e Arthur Neiva, que percorreu os estados da Bahia, Pernambuco, Pará, Goiás, Ceará, Amazonas, Tocantins, Acre, Espírito Santo, São Paulo e Mato Grosso. Entre outros resultados, a expedição gerou um documento que ficou conhecido com 'Relatório Neiva-Penna' (Neiva et al., 1918). Reuniu um significativo acervo de imagens produzidas com o objetivo de diagnosticar as doenças que assolavam o país, as condições de vida, saúde e habitação, além das práticas de higiene adotadas. Estavam lançadas as principais idéias que posteriormente viriam a subsidiar um amplo debate a respeito dos problemas sanitários nacionais.

Nesse contexto ganhou destaque a Liga Pró-Saneamento. Fundada em 11 de fevereiro de 1918, o movimento pretendia chamar a atenção para a necessidade de saneamento do interior do país e para o cuidado à saúde dos indivíduos, de modo a redescobrir os sertões. Ela era a expressão, em grande parte, do movimento sanitarista, tendo encabeçado a campanha pelo saneamento rural, com impacto significativo sobre a sociedade brasileira. O Estado passava a abordar a doença como um problema político, constatando o atraso e o abandono em que se encontrava a quase totalidade da população rural. Evidenciava-se assim a trilogia doença, sociedade e poder público.

O sanitarista Belisário Penna era um crítico do sistema federalista, não acreditando que a autonomia dos estados pudesse contribuir para a unidade das práticas judiciais, administrativas, educacionais e sanitárias. Ator de notável relevância na história da saúde pública, proferiu diversos discursos, registrados pela imprensa, em instituições políticas e científicas, além de ter atuação como líder da Liga Pró-Saneamento do Brasil entre 1918 e 1930; e como ocupante interino do Ministério da Educação e Saúde, de julho a dezembro de 1931, em substituição a Francisco Campos. Na tentativa de estruturar um serviço sanitário centralizado que atendesse à demanda nacional, a Liga Pró-Saneamento apontava para a necessidade da criação de um Ministério da Higiene e Saúde Pública e um Departamento Nacional de Saúde Pública.

Ainda dentro dessa perspectiva de centralização administrativa dos serviços sanitários, em 1919, e em meio a uma crise sanitária gerada pela epidemia de gripe espanhola, foi indicado o cientista Carlos Chagas para o cargo de diretor do Departamento Geral de Saúde Pública. Carlos Chagas foi um pesquisador de grande renome, oriundo dos quadros do IOC e teve o próprio Oswaldo Cruz como 
mentor. Sucedeu-o após sua morte em 1917 à frente do IOC. Empossado como diretor do Departamento Geral de Saúde Pública, organizou uma ampla reforma nos serviços sanitários federais, criando no ano seguinte o Departamento Nacional de Saúde Pública (DNSP). O sanitarista destacou-se pela elaboração do regulamento desta agência, considerada à época como a mais completa no que dizia respeito a assuntos de higiene.

\section{Os anos $1920-30$}

A idéia central de Carlos Chagas era a implantação de um modelo de organização sanitária, influenciado pelas idéias dos 'jovens turcos’2 em que se fazia necessário o investimento na formação de recursos humanos altamente qualificados para enfrentar os problemas do desenvolvimento nacional. A formação do grupo denominado 'jovens turcos' era resultado de uma visão norte-americana, segundo a qual o alto padrão de vida do povo dos Estados Unidos seria conseqüência da aplicação de avançadas técnicas sanitárias, e não produto do desenvolvimento econômico e social do país.

A opção de Chagas em investir na qualificação de pessoal cujas funções se ligavam às atividades de saúde pública manifestou-se na criação, em 1922, da Escola de Enfermagem Ana Nery; do curso de higiene e saúde pública da Faculdade de Medicina do Rio de Janeiro (1925) e do curso de higiene e saúde pública (1925) — pré-requisito para o curso de aplicação do Instituto Oswaldo Cruz.

Em 1916 a Fundação Rockefeller ${ }^{3}$ deu início à sua atuação no Brasil com a divulgação de um relatório que continha os resultados da investigação feita pelas expedições enviadas à América Latina. Diagnosticava-se a carência de base científica sólida para dar suporte a políticas públicas de consistência no continente; a ausência de treinamento médico quanto a questões de saúde pública e de carreiras especializadas para atuar nos serviços de saúde.

A partir dessa situação a fundação criou no Brasil um serviço de combate às verminoses no Nordeste. No mesmo ano, a Divisão Internacional de Saúde da Fundação Rockefeller estabeleceu no país um escritório regional, que aqui permaneceu até 1942, com o intuito de receber uma comissão de pesquisadores estrangeiros. Em cooperação com o governo brasileiro, esses pesquisadores pretendiam

\footnotetext{
'Jovens turcos' era a forma como se conheciam os sanitaristas brasileiros que iam para os Estados Unidos a fim de complementar sua formação médica. Ao voltar tentavam impor suas idéias baseadas na experiência adquirida naquele país de maneira extremamente autoritária, a exemplo da atuação dos jovens oficiais que ascenderam ao poder na Turquia após o golpe militar do marechal Ataturk.

${ }^{3}$ A Fundação Rockefeller foi criada em 1913, por iniciativa do milionário John D Rockefeller, com o objetivo de implantar em vários países medidas sanitárias baseadas no modelo americano, com a prioridade de empreender o controle internacional da febre amarela e da malária.
} 
elaborar estudos, propor e executar ações de saúde, a fim de se estabelecer um controle epidemiológico, erradicando a febre amarela no país. Tais medidas entraram em vigor com o apoio de Carlos Chagas, quando chefiava a diretoria do DNSP.

Como diretor deste departamento, Carlos Chagas convidou a enfermeira Ethel Parsons - do Serviço Internacional de Saúde da Fundação Rockefeller e chefe da missão técnica de cooperação para o desenvolvimento da enfermagem no Brasil - para montar o Serviço de Enfermeiras do Departamento e a Escola de Enfermagem Ana Nery. Esta escola exerceu papel estratégico na elaboração de uma nova política e de um novo modelo de saúde pública que começava a se delinear na década de 1920, sob a influência da Fundação Rockefeller. Centrava-se na modernização dos serviços e na implementação de cursos que atendessem às necessidades de um quadro de recursos humanos mais qualificado.

Nos anos 1920, pela primeira vez a saúde surgia como questão social no Brasil. Com o crescimento da economia cafeeira, a aceleração do processo de urbanização e o desenvolvimento industrial, a questão da saúde ganhou novos contornos, pois as condições sanitárias afetavam diretamente a qualidade da mão-de-obra. As medidas de saúde pública caracterizaram-se pela tentativa de modernização e extensão de seus serviços por todo o país. A reforma promovida por Carlos Chagas em 1923, criando o DNS, visava incorporar o saneamento rural, a propaganda sanitária e a educação higiênica como preocupações do Estado.

Nesse processo de implantação de políticas públicas de saúde destacou-se ainda o sanitarista Clementino Fraga, que já em 1906 entrou em contato com Oswaldo Cruz, participando das campanhas sanitárias de 1903 a 1909. Em 1917 assumiu a chefia da Comissão Sanitária Federal da Bahia, ocupando-se ainda do combate à febre amarela. No ano seguinte, colaborou com Carlos Chagas no combate à epidemia de gripe espanhola, e em 1926 sucedeu Carlos Chagas na direção do DNSP. Sua gestão destacou-se mais uma vez pelo combate ao surto de febre amarela no Rio de Janeiro nos anos 1927-28. A saída de Clementino Fraga do DNSP foi motivada pela Revolução de 1930, e ele foi substituído por Belisário Penna, antigo companheiro de jornadas sanitárias e naquele momento seu opositor político.

Embora afastado do DNSP, Clementino Fraga dedicou-se ao estudo da tuberculose no Hospital São Sebastião, que fora recuperado durante sua gestão. $\mathrm{Na}$ estrutura organizacional da saúde daquela agência (Fonseca, op. cit., p. 3) destacava-se aquele hospital como expoente, subordinado ao Serviço de Assistência Hospitalar da Diretoria Geral.

A estrutura do DNSP funcionava como coluna vertebral da organização da saúde pública no Brasil à época, sendo responsável pela projeção do modelo assistencialista - que teve como uma de suas maiores referências o Instituto Oswaldo Cruz -, chegando até a constituição do Ministério da Saúde em 1953. 
O Arquivo Pessoal Clementino Fraga também integra o acervo do DAD/COC é composto por séries que contemplam a correspondência do titular com Carlos Chagas, seu mais freqüente interlocutor. Outra série deste arquivo, denominada Departamento Nacional de Saúde Pública, é formada por documentos que abrangem o período de 1926 a 1940. Nela podem-se acompanhar diversas medidas administrativas desenvolvidas ao longo do mandato do sanitarista à frente da principal instituição de saúde pública da época.

De tudo o que já foi exposto, podemos concluir que a década de 1920 foi marcada pela criação de um arcabouço institucional que defendia uma política pública de saúde de abrangência nacional e visava promover a saúde da população por meio de práticas de higiene e interiorização das ações de saúde.

\section{Os anos 1930-53}

Em 14 de novembro de 1930 foi criado, pelo decreto 19.402, o Ministério dos Negócios da Educação e Saúde Pública. Dessa forma, as duas áreas, antes subordinadas ao antigo Ministério da Justiça e Negócios Interiores, passavam a ter pasta própria. Segundo o que dispunha o artigo $4^{\circ}$ do decreto, "poderão ser transferidos para o novo ministério serviços e estabelecimentos de qualquer natureza...". Assim sendo, o DNSP foi incorporado ao novo ministério, com a denominação de Departamento Nacional de Saúde e Assistência Médico-Social. Com a reforma administrativa do governo Vargas de 1934, transformou-se no Departamento Nacional da Saúde.

Outro decreto importante para o entendimento da criação do novo ministério foi o $19.444,{ }^{4}$ de $1^{\text {o }}$ de dezembro de 1930 , dispondo sobre os serviços que ficariam a cargo do Ministério da Educação e Saúde Pública e dando outras providências. No artigo $1^{\circ}$ trazia a composição do Ministério da Educação e Saúde Pública, que seria: de um gabinete, uma diretoria e quatro departamentos (Departamento Nacional de Ensino, Departamento Nacional de Saúde Pública, Departamento Nacional de Medicina Experimental e Departamento Nacional de Assistência Pública), todos independentes entre si e imediatamente subordinados ao ministro.

A aceleração do processo de urbanização, a ampliação da massa trabalhadora em precárias condições de higiene, saúde e habitação, a acumulação de capital industrial, próprios dessa economia em expansão, todos esses aspectos faziam com que a sociedade demandasse políticas sociais capazes de dar conta dos problemas mencionados, sobretudo os de saúde. O Estado passou a não mais responder à questão social de maneira parcial e policial, à proporção que os problemas de saúde

\footnotetext{
${ }^{4}$ Publicado na Coleção de Leis do Brasil. Capturado em 16.10.2003. On line. Disponível na Internet. http://.www.mec.gov.br/organiza/ftp/d19.444.
} 
passaram a ser tratados como fatos políticos inseridos nas relações de poder.

Nesse período a previdência social começava a se institucionalizar por meio dos institutos de aposentadoria e pensões (IAPs), organizados por categorias profissionais, e com eles começava a existir assistência médica previdenciária. Por intermédio dessas autarquias, os IAPs, o Estado passava também a controlar a concessão de benefícios no âmbito da seguridade social.

O acervo de história oral da COC possui um importante catálogo de depoimentos referente ao projeto Memória da Assistência Médica da Previdência Social (Fiocruz, 1989), no qual estão disponibilizadas cerca de quatrocentas horas em depoimentos das principais lideranças do movimento trabalhista que lutava pela política previdenciária.

A partir do golpe de 1937, o DNS foi reestruturado e dinamizado, passando a englobar vários serviços dispersos e a centralizar a direção política, administrativa e financeira de todas as atividades sanitárias do país, dentro do espírito de regime de exceção do Estado Novo. Na área da saúde, o executor dessa política foi o diretor do DNS, o sanitarista João de Barros Barreto. Oriundo do grupo dos 'jovens turcos', teve marcante atuação na política de saúde pública do governo Vargas.

As atividades de saúde pública obtiveram então grande impulso, inclusive beneficiando-se do desenvolvimento e ampliação dos serviços de saúde na década anterior. O DNS ampliou a rede pública de centros e postos de saúde, e, no plano da medicina curativa, instalou hospitais gerais, sanatórios para tuberculose, leprosários etc.

A política de saúde do Estado Novo foi portanto marcadamente centralizadora. Caracterizou-se pela estruturação dos departamentos estaduais de saúde com a seguinte composição: uma diretoria, uma coordenação de órgãos centralizados — tais como o de combate à tuberculose e à lepra - e uma coordenação dos órgãos descentralizados nos centros de saúde e postos e higiene para a área rural. Durante esse período deu-se a intensificação do sanitarismo campanhista, crescente desde a gestão de Carlos Chagas no DNSP.

O DNS desenvolveu os chamados serviços nacionais de saúde, entre eles o Serviço Nacional de Febre Amarela, em 1937, primeiro serviço de saúde pública de dimensão nacional; e o Serviço de Malária do Nordeste, em 1939, ambos em convênio com a Fundação Rockefeller, que estreitava sua cooperação com o governo brasileiro naquele momento. Além destes, foi criado também o Serviço Cooperativo da Febre Amarela, subordinado ao DNS, responsável pela profilaxia em âmbito nacional. Segundo Hochman (1998), as atividades da Fundação Rockefeller acompanharam a interiorização e a diversificação do próprio Estado brasileiro no campo da saúde pública.

Em 1942 a Fundação Rockefeller se retirou do Brasil, não sem antes criar o Serviço Especial de Saúde Pública (SESP). Por razões de ordem estratégica, ligadas à produção de borracha na Amazônia, o SESP 

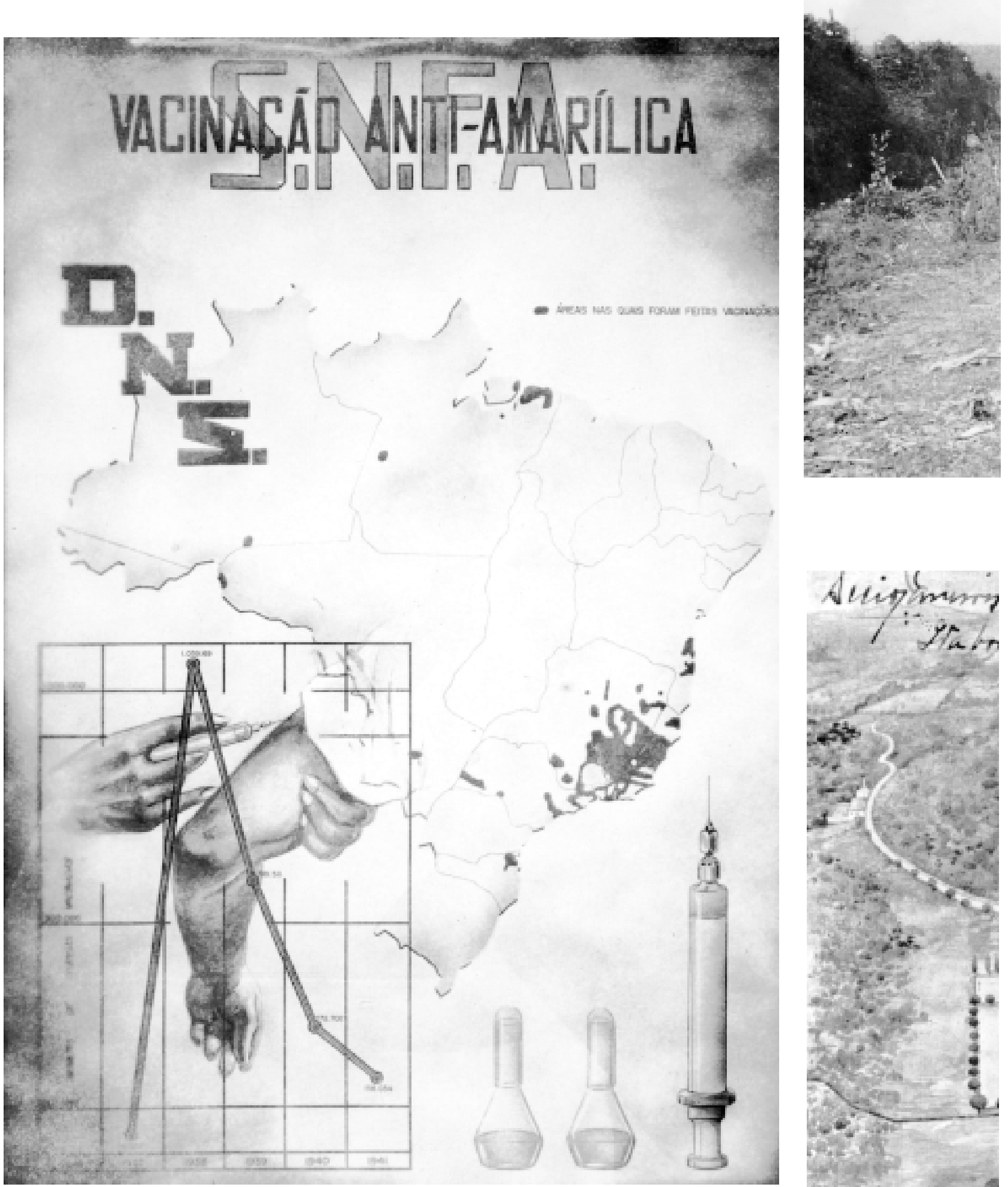

Cartaz do Serviço Nacional de Febre Amarela atestando a eficácia da aplicação da vacina produzida no Brasil a partir de 1937. Exposto na XI Conferência Sanitária Pan-Americana no Rio de Janeiro em 1942.

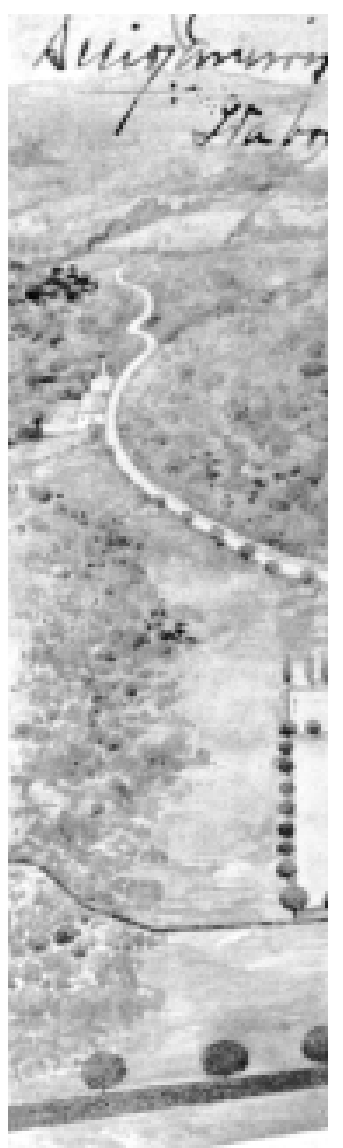




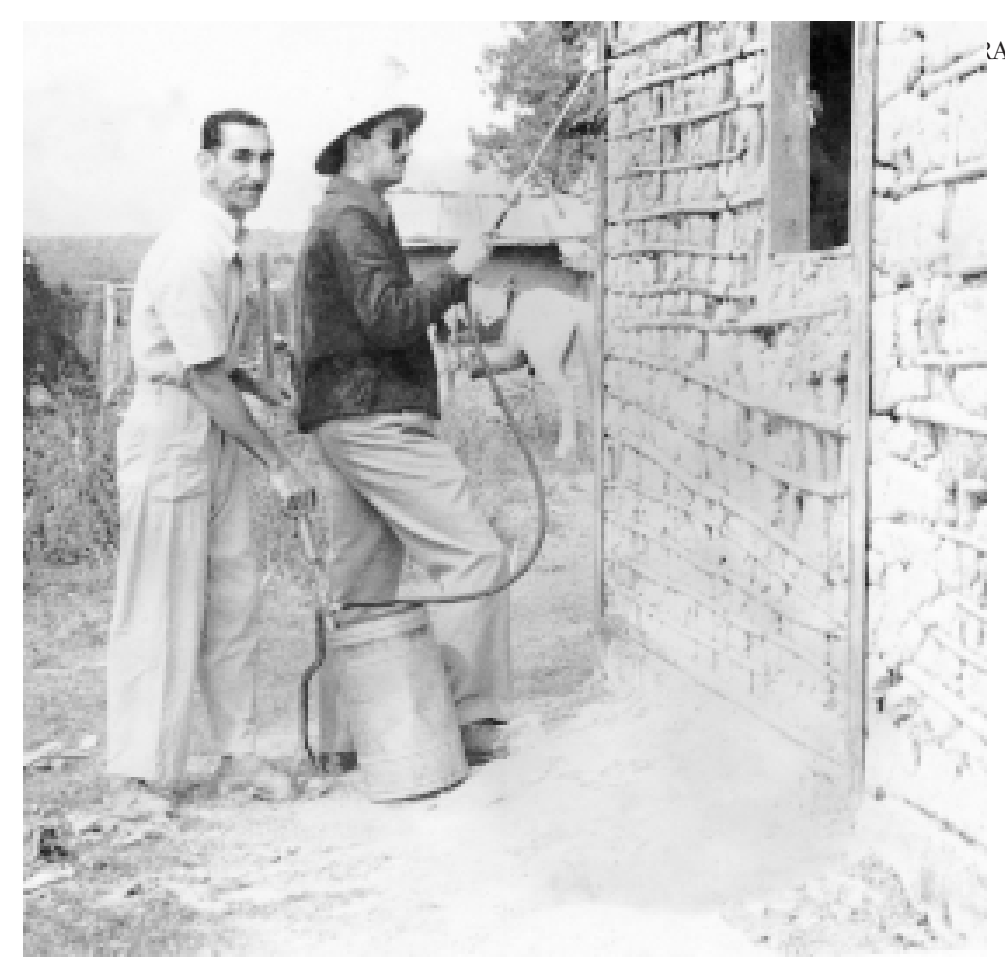

Emmanuel Dias, pesquisador do Centro de Pesquisas René Rachou, fumigando inseticida em moradia. Bambuí, Minas Gerais (década de 1940).

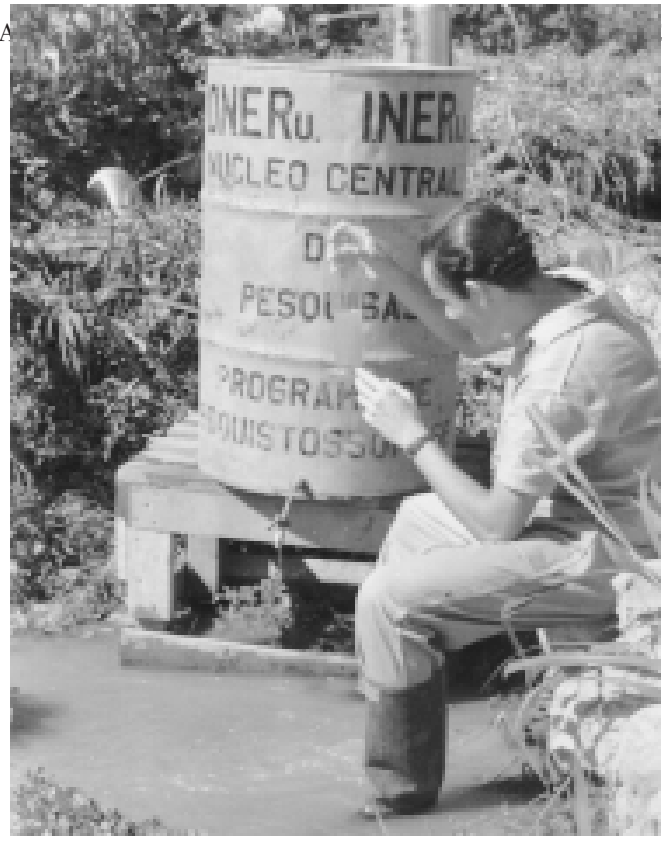

Agente sanitário atuando no controle e combate à esquistossomose, investigando a natureza e o comportamento etiológico da doença. Núcleo Central de Pesquisas, ligado ao Departamento Nacional de Endemias Rurais do Instituto Nacional de Endemias Rurais (décadas de 1950 e 1960).

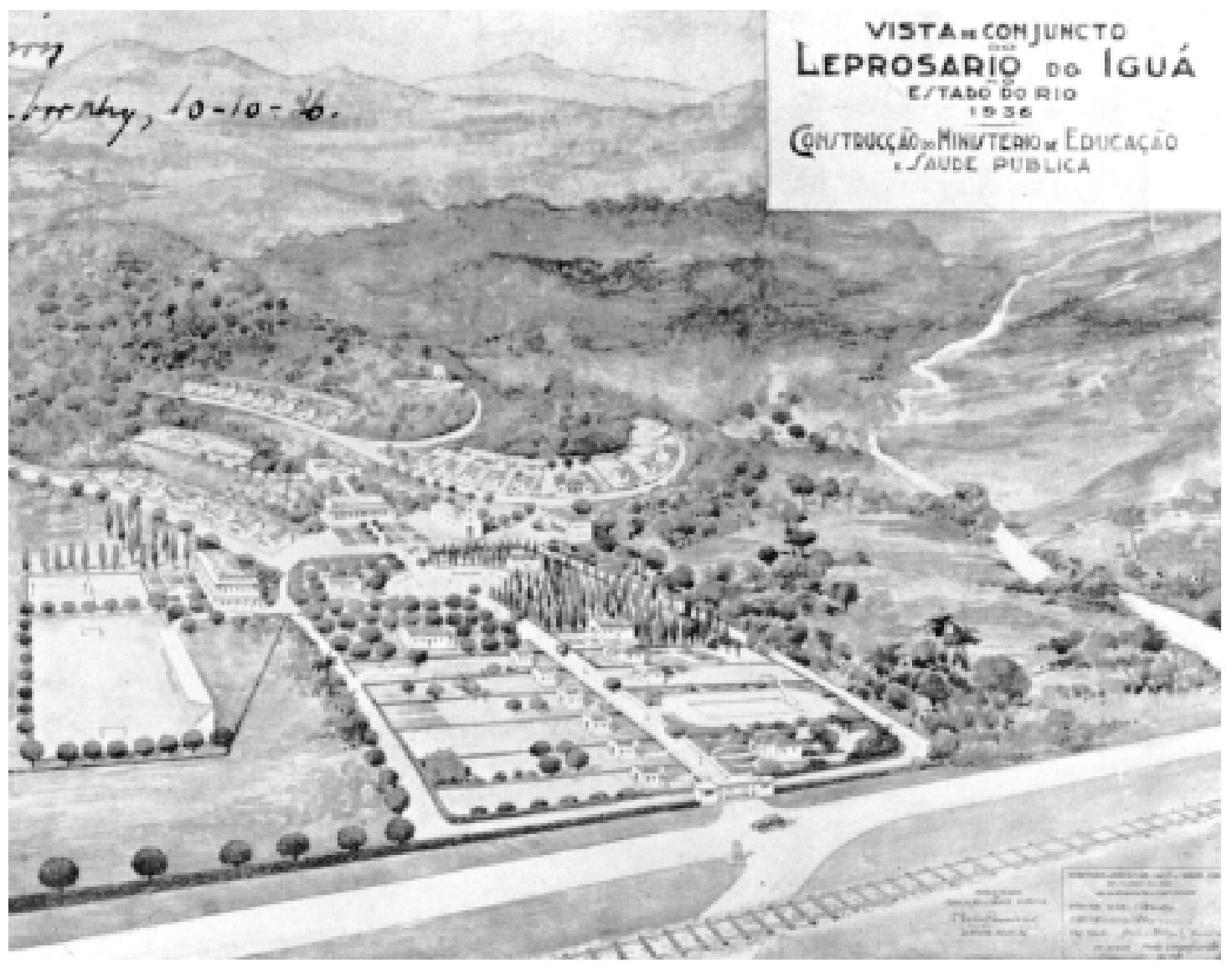

Vista do conjunto do Leprosário de Iguá no estado do Rio de Janeiro (1936). Construção do Ministério de Educação e Saúde Pública. 
passou a atuar prioritariamente naquela região, combatendo a malária e a febre amarela, os maiores flagelos a dizimar a mão-de-obra nos seringais. Sua estrutura baseava-se no modelo norte-americano de organização vertical, com unidades sanitárias extremamente dispendiosas, sempre perseguindo a mesma eficácia alcançada nas campanhas realizadas nos Estados Unidos. Um de seus objetivos era montar nas áreas rurais sistemas de atendimento à saúde diversificados. Instalava postos de saúde ou hospitais, arcando inicialmente com os custos de implantação (os gastos passavam paulatinamente para os governos estaduais e municipais).

As atividades do SESP sofreram uma expansão nos anos 1950, passando a abranger assistência médica, educação sanitária, saneamento, combate à malária, controle de doenças transmissíveis e desenvolvimento de pesquisas de medicina tropical, em convênio com o Instituto Evandro Chagas. Em 1960, esse serviço passaria à categoria de fundação, vinculada ao Ministério da Saúde pela lei 3.750. Adquiriu caráter permanente, expandindo territorialmente sua atuação a todas as unidades da Federação e no plano municipal, por meio de contratos de construção de sistemas de abastecimento d'água e tratamento de esgotos. Realizou também programas de promoção de saúde no Nordeste, em convênio com organismos internacionais, como a Agência Americana para o Desenvolvimento Internacional (Usaid), a Organização Pan-Americana de Saúde (Opas) e o Fundo das Nações Unidas para a Infância (Unicef).

Há no acervo da Fiocruz parte do Arquivo Permanente do Serviço Especial de Saúde Pública, cujas datas-limites estendem-se de 1942 a 1982, com concentração para as décadas de 1940, 1950 e 1960, abrangendo primordialmente sua criação e posterior transformação em fundação. Os documentos desse órgão foram organizados da seguinte forma: Série Administração (estrutura jurídica, cursos, treinamentos e publicações, relatórios de negociações diplomáticas, de atividades desenvolvidas e dos cursos de formação dos profissionais da área da saúde); Série Assistência Médico-Sanitária (relata os programas de assistência médica aos migrantes que iam trabalhar na Amazônia, os acordos de cooperação sanitária realizados com estados e municípios, abrangendo o período de 1944 e 1967); Série Engenharia Sanitária (divide-se em subséries, como), saneamento básico, saneamento ambiental e construções civis abrangendo o período de 1945 e 1973.

Atuando paralelamente na formação e capacitação de recursos humanos para a saúde, o DNS organizava em vários estados do Brasil cursos de saúde pública de caráter rápido e intensivo, a partir de 1938. Em 1944 foram organizados os seguintes cursos: organização e administração sanitária; malária; lepra; tuberculose, câncer e peste; engenharia sanitária; estatística vital; técnicas de laboratório; higiene mental; organização e administração hospitalar; tracoma; doenças venéreas e nutrição. Estes três últimos cursos foram acrescentados pelo decreto 14.178 de 6 de dezembro de 1943. Além dos cursos, em 1941, 
no âmbito do Ministério da Educação e Saúde, o DNS incorporou vários serviços de combate a endemias. Em sua composição compreendia os serviços nacionais de tuberculose; peste; malária (unificando os serviços regionais); lepra; câncer; doenças mentais. Também institucionalizava as campanhas sanitárias e assumia a organização pela educação sanitária, ao incorporar o Serviço Nacional de Educação Sanitária (1941), passando a controlar a formação dos técnicos em saúde pública. Além dos já mencionados, o DNS também incorporava o Serviço Nacional de Febre Amarela (1937), o Departamento Nacional da Criança (1940), o Serviço Nacional de Educação Sanitária (1941), o Serviço Nacional de Fiscalização da Medicina, o Serviço Federal de Bioestatística e o Serviço Federal de Biometria Médica. Mantinha o curso de saúde pública, centralizando e integrando alguns cursos já existentes, inclusive no IOC.

Ao final da Segunda Guerra Mundial, os Estados Unidos, adotando uma política expansionista, estenderam seu controle a diversas áreas de influência, sobretudo na América Latina, que se tornou quase seu quintal. Dessa forma, em 1948 criou-se o primeiro plano global de desenvolvimento econômico-social brasileiro, com recursos financeiros dos Estados Unidos, o Plano Salte. Era evidente a preocupação das lideranças sanitárias com a discussão orçamentária proposta pelo plano. Os documentos acumulados por Raphael de Paula Souza — que dirigiu o Serviço Nacional de Tuberculose do Ministério da Saúde e atuou como Superintendente da Campanha Nacional de Combate à Tuberculose até 1951 - mostram a preocupação com a discussão orçamentária que envolve o período. O titular empenhou-se em guardar os jornais referentes ao programa de saúde elaborado pelo plano, bem como o andamento de obras iniciadas antes da campanha de 1948 e documentos (regulamentos, discursos e relatórios) relativos à $2^{\underline{a}}$ Conferência Nacional de Saúde, em dezembro de 1950.

Com a queda do Estado Novo, delineou-se uma crise crescente da política nacional de saúde, recolocando em debate a forma como vinham se estruturando os serviços de saúde. O sanitarista Mário Magalhães da Silveira surgiu então como liderança da nova escola sanitária no Brasil, que atingiu seu apogeu no início dos anos 1960: a Escola Nacionalista-Desenvolvimentista. A principal questão que esse movimento se colocava referia-se ao círculo vicioso pobreza versus doença, posto como linha de atuação do ideário dos 'jovens turcos'. Travava-se também um debate sobre a questão administrativa, girando em torno da centralização ou descentralização da estrutura sanitária indagava-se se os serviços de saúde deveriam ser municipalizados, administrados pelas comunidades locais ou deveriam seguir um modelo único, vertical e centralizado.

A criação do Departamento Nacional de Endemias Rurais (DNERu), em 1956, vinculado ao Ministério da Saúde. Esse órgão representava o movimento de estruturação de instituições de saúde pública, 
estabelecendo-se que atuaria tanto no combate a enfermidades endêmicas, sob a responsabilidade do DNS, quanto no combate a doenças remanescentes, como febre amarela, malária e peste. O DNERu organizou e implementou várias campanhas na área de saúde pública, entre as quais podemos citar: de erradicação da malária nos anos 1960 e 1970; de erradicação da varíola, iniciada em 1958; e a campanha nacional contra a lepra, em 1959.

\section{REFERÊNCIAS BIBLIOGRÁFICAS}

\section{Arquivos}

Setor de Arquivos Pessoais e de Outras Institutições (arquivos textuais)

Setor de Arquivo Institucional (arquivos textuais)

Setor de Arquivos de Imagem e Som/

Arquivo Iconográfico

Setor de Arquivos de Imagem e Som/

Arquivos Sonoros

\section{Volumes}

Almeida, Célia Maria de et al. 1982

Braga, José Carlos de Souza

1978

Casa de Oswaldo

Cruz/Fiocruz

1991

Dumas, Fernando dos $S$. e Thielen Eduardo V. (introdução histórica); Medeiros, Alexandre (crônica da viagem) 1996

Fonseca, Cristina e Hamilton, Wanda set.-dez. 2003
Casa de Oswaldo Cruz/Departamento de Arquivo e Documentação.

Arquivo Belisário Penna; Arquivo Cláudio Amaral; Arquivo Clementino Fraga; Fundo Família Chagas, subconjuntos Carlos Chagas e Evandro Chagas; Arquivo Fundação SESP; Arquivo Heráclides César de Souza Araújo; Arquivo Oswaldo Cruz; Arquivo Raphael de Paula Souza.

Coleção História Administrativa da Fiocruz; Fundo Instituto

Nacional de Endemias Rurais.

Fundo Instituto Oswaldo Cruz/Subsérie Expedições; Fundo Belisário Penna; Fundo Fundação Rockefeller/Séries Serviço de Febre Amarela e Serviço de Malária do Nordeste; Fundo Família Chagas.

Memória da Assistência Médica da Previdência Social no Brasil; Revisitando a Amazônia de Carlos Chagas: da borracha à biodiversidade - etapa Negro e Branco; Revisitando a Amazônia de Carlos Chagas: da borracha à biodiversidade — etapa Acre/Purus.

'Financiamento das políticas de saúde no Brasil'. Em Saúde e trabalho no Brasil. Petrópolis, Vozes, pp. 61-79.

A questão da saúde no Brasil: um estudo das políticas sociais em saúde pública e medina previdenciária no desenvolvimento capitalista. Dissertação de mestrado. São Paulo: Universidade Estadual de Campinas, (mimeo.).

A ciência a caminho da roça: imagens das expedições científicas do Instituto Oswaldo Cruz ao interior do Brasil entre 1911 e 1913. Rio de Janeiro, Casa de Oswaldo Cruz/Fiocruz.

Revisitando a Amazônia de Carlos Chagas: expedição aos rios Negro e Branco refaz o percurso de Carlos Chagas em 1913. Fotografias: Rogério Reis e Flávio de Souza. Rio de Janeiro, Casa de Oswaldo Cruz/Fiocruz.

'Política, atores e interesses no processo de mudança institucional: a criação do Ministério da Saúde em 1953'. História, Ciências, Saúde-Manguinbos, vol. 10(3), pp. 703-17. 
Fonseca, Cristina (coord.)

1996

Fundação

Oswaldo Cruz

1989

Hamilton,

Wanda Susana

1993

Hamilton,

Wanda Susana

nov. 1989

Hochman, Gilberto

1998

Médici, André Cezar 1987

Neiva, Artur el al. 1918
Estrutura organizacional da saúde (1920-1990): relatório do Projeto PapesMemória da Saúde Pública no Brasil: políticas, concepções e bistória institucional — um projeto de história oral. Rio de Janeiro, DEPES/COC. (mimeo.)

Memória da assistência médica da Previdência Social: catálogo de depoimentos. Rio de Janeiro,PEC/ENSP, 192p. il.

O processo de criação do Ministério da Saúde. Rio de Janeiro, Casa de Oswaldo Cruz.

'Massacre de Manguinhos: crônica de uma morte anunciada'. Cadernos da Casa de Oswaldo Cruz, vol. 1, no 1, pp. 7-18.

A era do saneamento: as bases da política de saúde pública no Brasil. São Paulo, Hucitec/Anpocs.

'Financiamento das políticas de saúde no Brasil'. Boletim Oficina Sanitária Panamericana; vol. 103, nº 6, pp.571-98, dic.

Viagem científica pelo norte da Babia, sudoeste de Pernambuco, sul do Piauíe de norte a sul de Goiás. Rio de Janeiro, Instituto Oswaldo Cruz, 252p. ils. 